Article

\title{
Graphene Oxide/Fe-Based Composite Pre-Polymerized Coagulants: Synthesis, Characterization, and Potential Application in Water Treatment
}

\author{
Athanasia K. Tolkou * and Anastasios I. Zouboulis * $\mathbb{D}$ \\ Laboratory of Chemical and Environmental Technology, Department of Chemistry, \\ Aristotle University of Thessaloniki, GR-54124 Thessaloniki, Greece \\ * Correspondence: tolkatha@chem.auth.gr (A.K.T.); zoubouuli@chem.auth.gr (A.I.Z.); \\ Tel.: +30-2310-997794 (A.I.Z.); Fax: +30-2310-997730 (A.I.Z.)
}

Received: 14 June 2020; Accepted: 28 June 2020; Published: 30 June 2020 updates

\begin{abstract}
This study presents for the first time the synthesis and characterization of GO (graphene oxide), PFSiC (polyferric silicate chloride), and hybrid GO-PFSiC derivatives, aiming to enhance synergistically the performance of coagulation, when applied for the treatment of water. The structure and the morphology of composite GO-PFSiC coagulants were studied in detail by the application of FTIR, XRD, and SEM characterization techniques. Furthermore, the proposed coagulants were applied for the treatment of simulated turbid surface water. The effects of the reagent's dosage, $\mathrm{pH}$ value, and experimental/operational conditions on the coagulation efficiency, applied mainly for the removal of turbidity, were examined. The results, obtained from the FTIR and XRD measurements, showed the presence of a bond between the PFSiC and the GO surface, indicating that the PFSiC particles are distributed uniformly on the surface of graphene, which was also confirmed by the SEM images. Especially, the composite compound GO-PFSiC $1.5-15-0.5$ presents the most uniform distribution of iron on the surface of graphene oxide and exhibits the optimum coagulation efficiency, while it significantly reduces the turbidity for doses above $3-5 \mathrm{mg} / \mathrm{L}$, i.e., achieving the respective legislation limit as proposed by WHO. Specifically, at the alkaline $\mathrm{pH}$ values (>7.9), the removal of turbidity reaches $96 \%$. Consequently, the results of this study render these materials as potential coagulant agents for further research and applications, aiming to also achieve the co-removal of other water components.
\end{abstract}

Keywords: graphene oxide; pre-polymerized coagulants; composites; Fe-based; water treatment; coagulation

\section{Introduction}

The rapid development of nanomaterials, which present the advantages of larger surface areas and more activated functionalized sites, brings an alternative way for the preparation of novel specific reagents, dedicated to enhanced water purification [1,2]. Carbon-based nanomaterials are the most known representatives in this category, due to their numerous unique advantages, and considerable number of existing studies [3-6]. The most promising materials for treating and delivering pure water are considered those that incorporate nanoscale features and tailorable chemical properties [7].

Graphene [8,9], a two-dimensional (2-D) material, has attracted increasing interest in the field of composite materials, because of its excellent thermal [10], electrical [11], and mechanical [12] properties. This unique 2-D plane structure, coupled with an extremely high surface area, makes graphene an ideal support material. Multifunctional hybrid materials that can take advantage of the extraordinary 
properties of both graphene and other participating functional materials have been already reported [13-16]. In addition, graphene oxide (GO) can be readily obtained from cheap natural graphite in large quantities. Thus, hybrid multifunctional materials based on GO can be much more applicable, than those, e.g., based on other relatively more expensive nanomaterials, such as the functionalized one-dimensional carbon nano-tubes (CNTs). Recently, GO-based composite materials have been applied for the removal of certain inorganic pollutants from water sources [17]. Another challenge is the environmental concerns, regarding GO materials. Although previous reports $[18,19]$ indicate that GO has better biocompatibility than CNTs, the exposure to residual GO in water may still pose possible risks to human health. Noting, however, that the relevant literature is rather limited $[18,19]$ and inconsistent results have been reported, showing that GO can exhibit either nontoxicity or dose-dependent toxicity. Therefore, more detailed investigation concerning these issues is necessary.

Coagulation, which is a widely applied process, especially for water treatment, because of its high efficiency and facile operation, is considered among the most important industrial technologies for water/wastewater treatment, noting that the appropriate selection and application of coagulant reagents during this process is significant, thus affecting its final performance. In fact, previous studies [17] have already shown that GO is an efficient absorbent to remove metal ions and various types of organic matter and pollutants from water sources. On the other hand, there are some reports in the literature about the incorporation of GO flakes within a membrane material with the aim of water desalination and/or purification, thus optimizing water transport through graphene-based membranes [20]. Membrane fouling is considered as the main process drawback. A graphene-based nanocomposite membrane dip-coated by polydopamine (PDA), which is known for its antifouling properties, was proposed [21]. The presence of GO also increased the mechanical stability of the membrane. However, a rather limited number of publications have addressed the subject of using GO as a coagulant reagent so far [22-24].

The pre-polymerized inorganic coagulants represent a relatively new category of coagulant agents, which was developed in order to increase the effectiveness of the convenient coagulation process. More recently, composite polymeric aluminum and/or iron products, such as PFSiS (polyferric silicate sulfate) [25], PASiC (polyaluminium silicate chloride) [26], PSiFAC (poly aluminum ferric silicate chloride) [27], and PSiFAC-Mg (poly aluminum ferric silicate magnesium chloride) [28], have been examined during mainly laboratory experiments, regarding, for example, the removal of turbidity [27], arsenic [29], and high-strength industrial wastewaters [30], as well as for the reduction of membrane fouling in MBR (Membrane bioreactor) systems [31].

This study presents for the first time the combined application of GO (graphene oxide) and PFSiC (polyferric silicate chloride) materials, i.e., an Fe-based composite pre-polymerized coagulant reagent, as a promising approach to synergistically enhance the water treatment, taking into account the specific advantages of each material. To the best of our knowledge, this category of combined coagulants has never been previously applied for water treatment, while the use of hybrid GO-PFSiC reagent is firstly reported in the literature. The structure and the morphology of composite GO-coagulants were studied in detail by the application of FTIR, XRD, and SEM characterization techniques. Furthermore, the proposed coagulants were applied for the treatment of simulated surface water contaminated with clay. The World Health Organization (WHO) has established that the turbidity of drinking water should be not more than 5 NTU, and should be better below 1 NTU [32].

\section{Materials and Methods}

All used chemical reagents were of analytical grade. De-ionized water (with low conductivity, $<0.5 \mu \mathrm{S} / \mathrm{cm}$ ) was used to prepare all solutions, while de-ionized carbonate-free water was used for the preparation of stock solutions, regarding the coagulants. 


\subsection{Preparation of Graphene Oxide (GO)}

The graphite flakes, used for the preparation of graphene oxide, were purchased from Sigma Aldrich (USA). Graphite oxide (GrO) was prepared by using the modified Hummer's method [33], as improved by Debnath et al. (2014) [34]. In brief, graphite flakes (5.0 g) and $\mathrm{NaNO}_{3}(2.5 \mathrm{~g})$ were mixed with $120 \mathrm{~mL}$ of $\mathrm{H}_{2} \mathrm{SO}_{4}(95 \%)$ in a 500-mL flask. The mixture was stirred for $30 \mathrm{~min}$ in an ice bath. Afterwards, $15.0 \mathrm{~g} \mathrm{KMnO}_{4}$ was added into the mixture under vigorous stirring, keeping the reaction temperature lower than $20^{\circ} \mathrm{C}$. The mixture was further stirred at room temperature overnight. Thereafter, another $15.0 \mathrm{~g}$ of $\mathrm{KMnO}_{4}$ were added into the previous mixture and stirred at room temperature for another $2 \mathrm{~h}$, aiming to oxidize totally any remaining graphite. On addition of the deionized water into this mixture, a yellowish paste was obtained, and the temperature was increased to about $98^{\circ} \mathrm{C}$ with effervescence. This diluted suspension was then stirred for another $4 \mathrm{~h}$ and $50 \mathrm{~mL}$ of $\mathrm{H}_{2} \mathrm{O}_{2}(30 \%)$ were added afterwards to the mixture. As the reaction progressed, the color of the pasty mixture gradually turned into light brownish. The mixture was subsequently washed with $100 \mathrm{~mL}$ of $5 \% \mathrm{HCl}$ and $30 \% \mathrm{H}_{2} \mathrm{O}_{2}$ (five times) to purify it from any residuals of $\mathrm{MnO}_{2}$ and sulfates. Finally, a solid was obtained after drying at $60{ }^{\circ} \mathrm{C}$ under vacuum.

Graphene oxide (GO) was prepared from the solid graphite oxide by sonicating the solid in double distilled water, aiming to convert it into a stable colloidal suspension. Then, the colloidal graphene oxide (GO) was precipitated by using $0.1 \mathrm{M} \mathrm{NaOH}$ solution and the solid precipitates were subsequently filtered through a $0.45-\mathrm{mm}$ nylon membrane filter to separate the liquid phase and finally, they were subjected to drying at $60^{\circ} \mathrm{C}$ under vacuum and the $\mathrm{GO}$ was obtained as grey powder.

\subsection{Preparation of PFSiC}

Composite poly-ferric-silicate chloride (PFSiC) coagulants were produced at room temperature $\left(22^{\circ} \mathrm{C}\right)$, according to a modified procedure of Zouboulis and Moussas (2008) [25] and Tolkou et al. (2015) [27] under various experimental conditions. The initial solutions used for the preparation of pre-polymerized coagulants were $0.5 \mathrm{M} \mathrm{FeCl}_{3} \cdot 6 \mathrm{H}_{2} \mathrm{O}$ (Merck) and $0.5 \mathrm{M} \mathrm{NaOH}$ (Merck, as the added alkaline agent). The $0.5 \mathrm{M}$ polysilicic acid solution ( $\mathrm{pSi}$ ) was prepared according to the respective literature [26]: $1.74 \mathrm{~mL}$ of $\mathrm{pSi}$ solution were added to $20 \mathrm{~mL}$ of $0.5 \mathrm{M} \mathrm{FeCl}_{3} \cdot 6 \mathrm{H}_{2} \mathrm{O}$ solution, under vigorous stirring $(0.3 \mathrm{~mL} / \mathrm{min}, 20 \mathrm{rpm})$, and subsequently, $30 \mathrm{~mL}$ of alkaline solution were added slowly under magnetic stirring $(0.1 \mathrm{~mL} / \mathrm{min}, 70 \mathrm{rpm})$ in the mixture at the temperature of $30^{\circ} \mathrm{C}$. The produced composite pre-polymerized material, termed as $\mathrm{PFSiC}_{1.5-15}$ to indicate the proportions of the aforementioned components, was left under stirring to mature for about $1 \mathrm{~h}$ and then diluted with water to the final concentration of $0.1 \mathrm{M}$ (relevant to Fe). The main physico-chemical properties of this coagulant agent (used in the subsequent experiments) were $\mathrm{pH}$ value 1.9, turbidity $65 \mathrm{NTU}$, and conductivity $29 \mathrm{~ms} / \mathrm{cm}$.

\subsection{Preparation of Composite GO-PFSiC Material}

The Fe-containing graphene oxide composite materials were prepared after the impregnation of prepared graphene oxide with the pre-polymerized Fe-based coagulant (PFSiC), followed by thermal treatment at $85^{\circ} \mathrm{C}$. For a typical impregnation procedure, taking, e.g., GO-PFSiC ${ }_{1.5-15-1}$ as a typical case with a molar ratio of $[\mathrm{GO}] /[\mathrm{Fe}]=1100 \mathrm{mg}$ of $\mathrm{GO}$ were dispersed in $100 \mathrm{~mL}$ of water $(1 \mathrm{~g} / \mathrm{L})$. The appropriate amount of aquatic solution of $\mathrm{PFSiC}_{1.5-15}$, i.e., $100 \mathrm{mg}$ Fe (as $17.3 \mathrm{~mL}$ of $0.1 \mathrm{M}$ coagulant solution) were added. Because of the highly acidic $\mathrm{pH}$ value of $\mathrm{PFSiC}_{1.5-15}$, the precipitation of ferric (hydro)oxide species [35] was avoided. After $30 \mathrm{~min}$ of stirring, the dispersion was sonicated for $30 \mathrm{~min}$. It was then filtrated, washed with deionized water, and finally, it was dried in the air. A weighed amount of dried impregnated graphene oxide composite was placed in a furnace and heated up overnight to $85^{\circ} \mathrm{C}$. Two more relevant materials, but with different molar ratios, were also synthesized by following the same procedure, i.e., $100 \mathrm{mg} \mathrm{GO} / 200 \mathrm{mg}$ Fe to obtain the ratio [GO]/[Fe] $=0.5$ and $100 \mathrm{mg} \mathrm{GO} / 333.3 \mathrm{mg}$ Fe to obtain the ratio $[\mathrm{GO}] /[\mathrm{Fe}]=0.3$, and the resulting impregnated GOs are 
presented in Table 1, while the weight ratio of Fe to GO was increased stepwise in order to define the most efficient coagulant.

Table 1. Preparation conditions for the laboratory-synthesized composite coagulant agents, examined in this study.

\begin{tabular}{|c|c|c|}
\hline Coagulant Type & Molar Ratios & Category \\
\hline GO & - & Graphene Oxide \\
\hline $\mathrm{PFSiC}_{1.5-15}$ & {$[\mathrm{OH}] /[\mathrm{Al}]=1.5 ;[\mathrm{Fe}] /[\mathrm{Si}]=15$} & $\mathrm{FeCl}_{3}+\mathrm{pSi}+\mathrm{NaOH}$ \\
\hline GO-PFSiC $_{1.5-15-1}$ & {$[\mathrm{OH}] /[\mathrm{Al}]=1.5 ;[\mathrm{Fe}] /[\mathrm{Si}]=15 ;[\mathrm{GO}] /[\mathrm{Fe}]=1$} & Fe-impregnated GO \\
\hline GO-PFSiC $_{1.5-15-0.5}$ & {$[\mathrm{OH}] /[\mathrm{Al}]=1.5 ;[\mathrm{Fe}] /[\mathrm{Si}]=15 ;[\mathrm{GO}] /[\mathrm{Fe}]=0.5$} & Fe-impregnated GO \\
\hline GO-PFSiC $_{1.5-15-0.3}$ & {$[\mathrm{OH}] /[\mathrm{Al}]=1.5 ;[\mathrm{Fe}] /[\mathrm{Si}]=15 ;[\mathrm{GO}] /[\mathrm{Fe}]=0.3$} & Fe-impregnated GO \\
\hline
\end{tabular}

\subsection{Characterization}

\subsubsection{Scanning Electron Microscopy (SEM)}

Small portions of coagulant powders were obtained after drying the aquatic solution of PFSiC in the oven $\left(\sim 40^{\circ} \mathrm{C}\right)$. GO and GO-PFSiC composites were already in powdered form and used to observe the morphology of respective products, by employing a ZEISS EVO 50 scanning microscope, at EHT $=10 \mathrm{kV}$. The SEM sample was prepared by placing a drop of dilute ethanol dispersion of the prepared composites onto a copper plate attached to an aluminum sample holder and the solvent was allowed to evaporate at room temperature.

\subsubsection{FT-Infrared Spectroscopy (FTIR)}

FTIR spectra of the prepared composite products were recorded in the range of $4000-400 \mathrm{~cm}^{-1}$, by using a Nicolet 380 FTIR Spectrometer-Thermo Scientific spectrophotometer to allow the observation of surface species and the possible polymeric interactions between the components.

\subsubsection{X-ray Diffraction Spectroscopy (XRD)}

The X-ray diffraction spectroscopy (XRD) is an important tool for the identification of crystalline compounds and it was applied to identify the possibly formed crystalline phases. The Malvern Panalytical Xpert instrument ( $\mathrm{Cu}-\mathrm{K}$ radiation) was used and the solid samples were analyzed in the range of $20^{\circ}-80^{\circ} 2 \theta$ with a scan rate of $1^{\circ} / \mathrm{min}$.

\subsection{Batch Coagulation Experiments}

\subsubsection{Coagulation Experiments Performed by Jar-Tests}

Convenient jar-test experiments were applied for the examination of coagulants' efficiency, by using a jar-test apparatus (Aqualytic), equipped with six paddles, employing 1-L glass beakers. The simulated contaminated surface water $(1 \mathrm{~L})$ was prepared by using tap water of Thessaloniki (N. Greece) and clay (kaolin) suspension of an initial concentration of clay suspended particles of $10 \mathrm{mg} / \mathrm{L}$. The $\mathrm{pH}$ was properly adjusted by using $\mathrm{HCl}$ or $\mathrm{NaOH}$ solutions of appropriate concentrations (1-0.01 M) and measured by a Metrohm Herisau $\mathrm{pH}$ meter. The properties of water samples are presented in Table 2, while the conditions used in the jar-test experimental runs are shown in Table 3.

Table 2. Initial sample properties (simulated surface samples).

\begin{tabular}{ccc}
\hline Type of Sample to Be Treated & Turbidity (NTU) & $\mathbf{p H}$ \\
\hline Simulated surface water & 17.2 & $7.6 \pm 0.2$ \\
\hline
\end{tabular}


Table 3. Experimental conditions of coagulation using simulated surface water samples.

\begin{tabular}{ccccc}
\hline \multicolumn{2}{c}{ Rapid Mixing Period } & \multicolumn{2}{c}{ Slow Mixing Period } & \multirow{2}{*}{ Sedimentation (min) } \\
\cline { 1 - 4 } Duration (min) & Mixing Rate (rpm) & Duration (min) & Mixing Rate (rpm) & \\
\hline $1-2.5$ & 160 & 10 & 40 & $30-60$ \\
\hline
\end{tabular}

\subsubsection{Turbidity Removal}

After the coagulation treatment, samples were collected from the supernatant of each beaker and were analyzed for the determination of turbidity (NTU), by using a HACH RATIO/XR Turbidimeter. In order to evaluate the synergistic effect of $\mathrm{GO}$ and PFSiC in water treatment, residual turbidity values, obtained by the application of combined materials, were compared with those obtained with standalone GO and PFSiC reagents.

For clay suspension, the residual turbidity percentage $(R T, \%)$ was expressed as:

$$
R T(\%)=\left(\frac{T}{T_{o}}\right) \times 100 \%
$$

where $T$ and $T_{o}$ are the turbidities of the treated and raw water, respectively.

\section{Results and Discussion}

\subsection{Characterization}

The characterization of the new composite materials by using FTIR measurements was carried out to confirm the bonding or types of functional groups of molecules that are being present in the $\mathrm{GO}$ and can be impregnated into the new GO-PFSiC materials. FTIR analysis was performed at wavenumbers $400-4000 \mathrm{~cm}^{-1}$, where in this range the characteristic absorption of functional group vibrations, as presented by the GO and the composites, can be identified. In Figure 1, the FTIR spectra can be shown, comparing the different examined materials, i.e., GO, $\mathrm{PFSiC}_{1.5-15}$, GO-PFSiC $1.5-15-1$, GO-PFSiC $_{1.5-15-0.5}$, and GO-PFSiC ${ }_{1.5-15-0.3}$. In the FTIR spectra, primary hydroxyl C-OH $\left(1380 \mathrm{~cm}^{-1}\right)$ groups, epoxy $\mathrm{C}-\mathrm{O}$ groups $\left(1186 \mathrm{~cm}^{-1}\right)$, and carbonyl $\mathrm{C}=\mathrm{O}\left(1820 \mathrm{~cm}^{-1}\right)$ groups can be detected in the $\mathrm{GO}$ spectrum, which reveals that large numbers of oxygen-containing groups have been introduced/interact into/with the GO structure [36,37]; noting also that there is an absence of absorption at the wavenumber $1725 \mathrm{~cm}^{-1}$, which matches with the characteristics of $\mathrm{C}=\mathrm{C}$ aromatic stretching vibration, indicating that GO is completely oxidized [38].

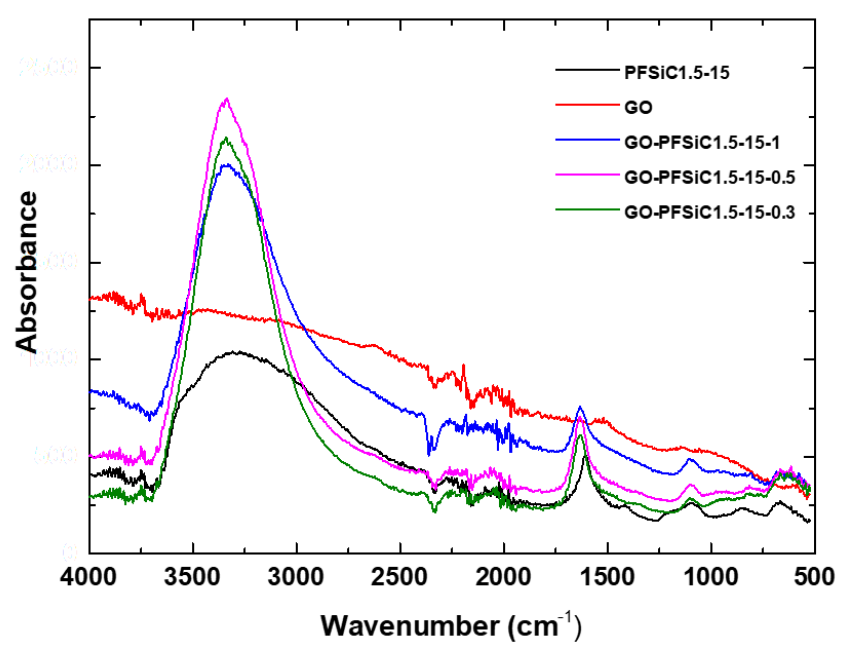

Figure 1. FTIR spectra comparing the examined materials GO, PFSiC $1.5-15$, GO-PFSiC $_{1.5-15-1}$, GO-PFSiC $_{1.5-15-0.5}$, and GO-PFSiC $1.5-15-0.3$. 
The band at $1038 \mathrm{~cm}^{-1}$, which was found only in the spectra of pre-polymerized coagulants, can be assigned to the asymmetric $\mathrm{Si}-\mathrm{O}$ stretching vibrations of $\mathrm{Si}-\mathrm{O}-\mathrm{Si}$ bonds, which is indicative of the high polymerization degree of silica. In addition, two characteristic peaks exist at 1100 and $1080 \mathrm{~cm}^{-1}$ that could be attributed to the asymmetric stretching vibration of $\mathrm{Fe}-\mathrm{O}-\mathrm{Fe}$ [30] and $\mathrm{Si}-\mathrm{O}-\mathrm{Fe}$ bonds [39], respectively. Moreover, in the spectra of $\mathrm{PFSiC}_{1.5-15}$ and also of the composites GO-PFSiC, it can be observed that there is a peak at the wavenumber $3279.75 \mathrm{~cm}^{-1}$, which indicates the characteristic absorption of stretching vibrations from the $-\mathrm{OH}$ group. The wide peaks in these vibration ranges are characteristic of $-\mathrm{OH}$ groups that undergo hydrogen bond formation. The absorption at the wave number $1623.36 \mathrm{~cm}^{-1}$ expresses the characteristic of vibration stretching from the $\mathrm{C}=\mathrm{C}$ group. FTIR analysis can also provide a strong clue to the formation of the co-ordination bond $\mathrm{C}-\mathrm{O}-\mathrm{Fe}$ between the GO sheets and the iron particles. This can be noticed from the presence of the characteristic absorption bands of the stretching vibrations of Fe-O in the PFSiC material that were found at the wavenumber $617.19 \mathrm{~cm}^{-1}$, which confirms the success of PFSiC loading/interactions with the GO sheets. The difference that can be observed between the FTIR spectrum of GO and the GO-PFSiC materials is that there is a weakening of the absorption intensity at the wave number around $1580 \mathrm{~cm}^{-1}$, regarding the composite GO-PFSiC, as compared to simple GO, which at the wave number $1580 \mathrm{~cm}^{-1}$ is considered as an absorption characteristic of the carboxyl group. This shows that there has been a reduction in the quantity of carboxyl groups, because they are playing role as a ligand that can interacts with the Fe atoms of PFSiC [38,40,41].

The morphology and structure of GO and of the relevant composites were further examined by obtaining representative SEM images of these materials. As typical examples, the SEM images of GO, PFSiC, and GO-PFSiC materials are shown in Figure 2. Both the pristine GO and the prepared impregnated GO-PFSiC materials were found to exhibit a typically wrinkled sheet-like structure, as it can be observed, indicating that iron was homogeneously distributed onto the GO sheets. Especially, the composite GO-PFSiC $1.5-15-0.5$, as illustrated in Figure $2 \mathrm{~d}$, presents the most uniform distribution of iron on the surface of graphene oxide.
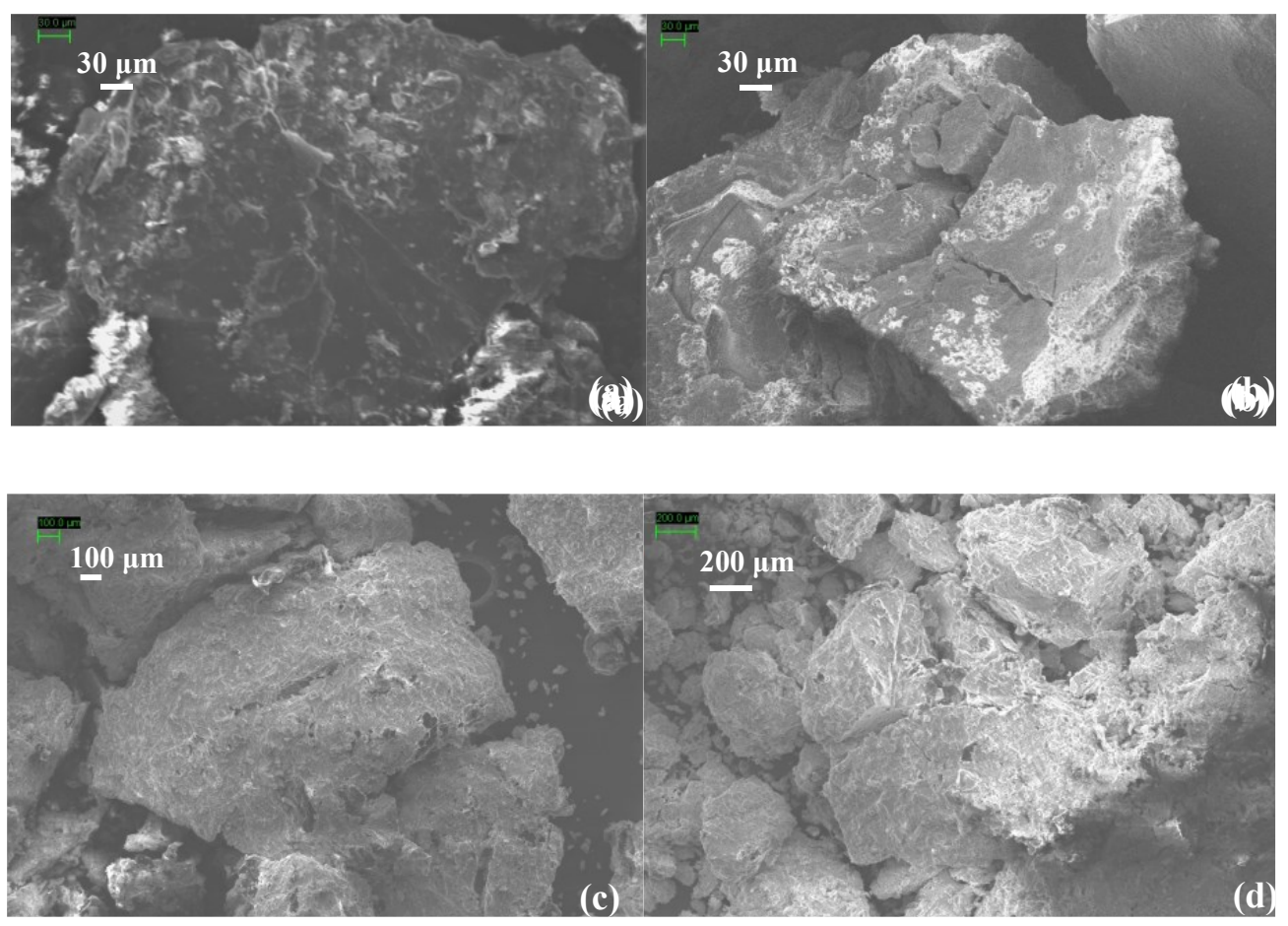

Figure 2. Cont. 


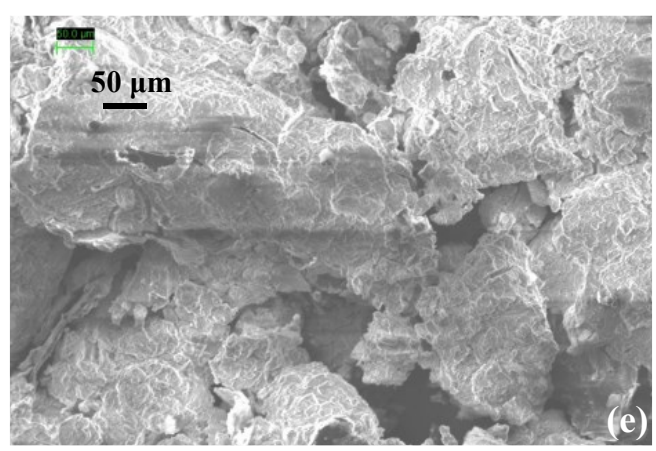

Figure 2. SEM images of hybrid/composite materials, obtained after convenient drying in an oven under constant rather low temperature $\left(\sim 40{ }^{\circ} \mathrm{C}\right)$; (a) GO; (b) $\mathrm{PFSiC}_{1.5-15}$; (c) GO-PFSiC $1.5-15-1$; (d) GO-PFSiC $1.5-15-0.5$; and (e) GO-PFSiC $1.5-15-0.3$.

The results obtained from the XRD analysis are presented in Figure 3 for the cases of GO (Figure 3a), PFSIC $_{1.5-15}$ (Figure $3 b$ ), and GO-PFSiC hybrids (Figure $3 c-e$ ). From the XRD patterns, similar diffraction peaks at $35.6^{\circ}, 43.3^{\circ}, 53.6^{\circ}, 57.3^{\circ}$, and $62.8^{\circ}$ in Figure $3 \mathrm{~b}-\mathrm{e}$ can be detected, which are the characteristic peaks of cubic Fe [42], indicating that the respective peaks of PFSIC $1.5-15$ are formed in the composites and that the PFSiC particles are distributed uniformly on the surface of graphene, which was also confirmed by the SEM images (Figure 2) [43].
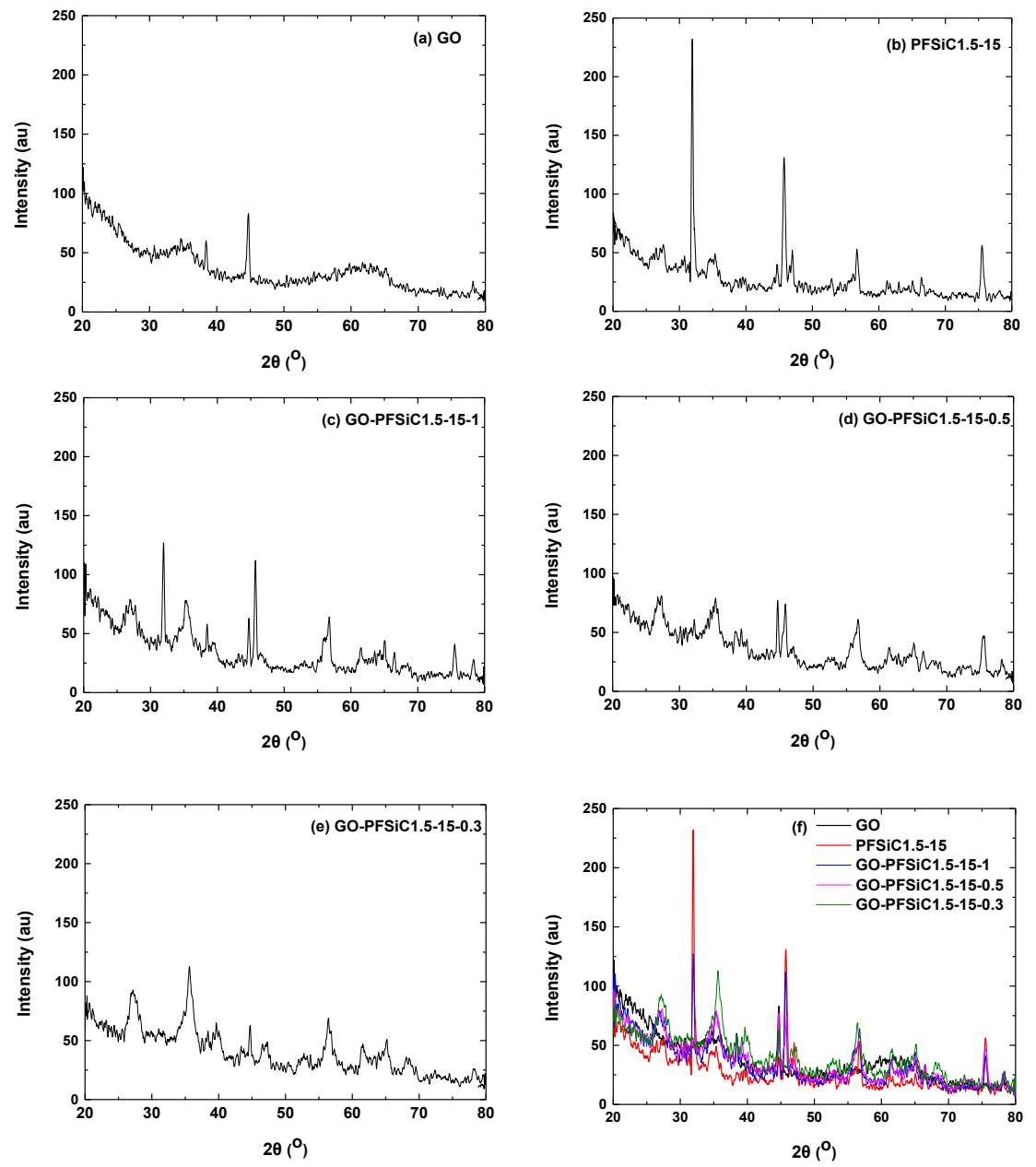

Figure 3. XRD diagrams of the examined materials; (a) GO, (b) $\mathrm{PFSiC}_{1.5-15}$, (c) GO-PFSiC $1.5-15-1$, (d) GO-PFSiC $1.5-15-0.5$, (e) GO-PFSiC $1.5-15-0.3$, and (f) comparison between them. 
It should be noted, however, that the intense and characteristic peak at $45^{\circ}$ belongs to the sample carrier during the analysis by the XRD instrument and not to another compound contained in the sample [24]. In addition, the sharp peak at $32^{\circ}$ is observed only in Figure $3 b$, which corresponds to $\mathrm{PFSiC}_{1.5-15}$, and belongs to $\mathrm{NaCl}$ that is produced during the preparation of $\mathrm{PFSiC}_{1.5-15}$ solution and it disappeared in Figure 3c-e, which present the XRD patterns of solid composite GO-PFSiC hybrids. However, it is observed that with the increase of the Fe/GO ratio (see Figure 3b-e, respectively), the intensity of the peak at $32^{\circ}$ gradually decreases, indicating that at a higher [Fe]/[GO] ratio, amorphous ferric hydroxide materials are intercalated between the GO sheets and a homogeneous amorphous composite is formed [13].

In addition, as shown in Figure $3 a$, GO material presents two characteristic peaks at $25.58^{\circ}$ and $38.8^{\circ}$, corresponding to the partially oxidized part that shows few layers of graphene, and to natural graphite, which undergoes imperfect oxidation, respectively. The presence of a bond between the PFSiC and the GO surface can be seen from the shift of the GO peak to $30.58^{\circ}$, which is caused by the reduction of some graphene oxides to graphene, due to the precipitation reaction of Fe ion $[38,44]$.

\subsection{Coagulation Performance}

\subsubsection{Determination of Optimum Coagulation Experimental Conditions}

In Figure 4, the results of the experiments, as applied for the determination of optimum coagulation conditions during jar-test experimental runs, are presented. For this reason, GO and PFSiC $1.5-15$ were compared, regarding the removal of turbidity and expressed as the residual turbidity (NTU), (a) in different sedimentation times, and (b) in different rapid mixing period times (Table 3), based on previous research tests [27], by using $10 \mathrm{mg} / \mathrm{L}$ as an indicative dosage.
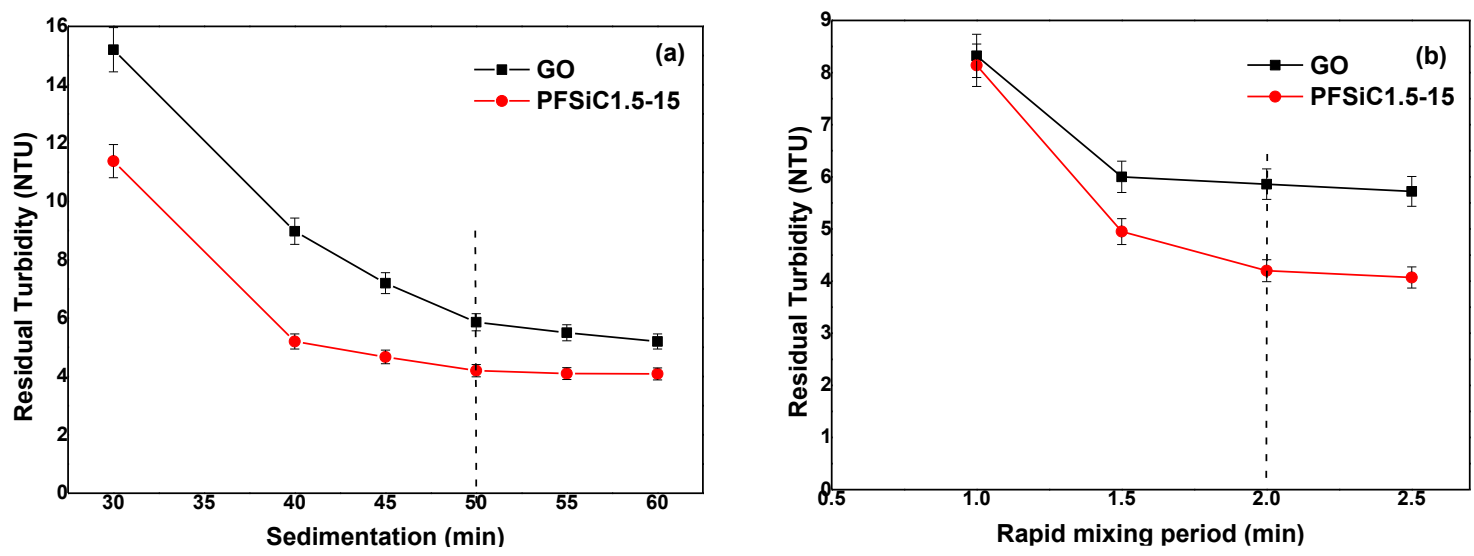

Figure 4. Determination of the optimum coagulation experimental conditions, comparing GO and PFSiC $_{1.5-15}$ materials, regarding the removal of turbidity (expressed as the residual turbidity, NTU); (a) by using different sedimentation times, and (b) by applying different rapid mixing period times.

Particularly, when studying the different applied sedimentation times (Figure 4a), the solutions were stirred rapidly at $160 \mathrm{rpm}$ for $2 \mathrm{~min}$, followed by slow stirring at $40 \mathrm{rpm}$ for $10 \mathrm{~min}$, and then, the suspension was rested for 30-60 min without any stirring to allow the separation by sedimentation of the produced flocs. As noticed in Figure 4a, the optimum sedimentation time was found to be $50 \mathrm{~min}$, where the system reaches a dynamic equilibrium, indicated by the relatively constant value of turbidity after 50 min of sedimentation.

Then, maintaining the optimal settling time at $50 \mathrm{~min}$, the different durations of the initial rapid mixing period (Figure 4b) were tested at $160 \mathrm{rpm}$ for 1, 1.5, 2, and $2.5 \mathrm{~min}$, followed by the slow stirring at $40 \mathrm{rpm}$ for 10 and $50 \mathrm{~min}$ of sedimentation. According to Figure $4 \mathrm{~b}$, the optimum time in this case was 2 min of rapid mixing. After that, the residual turbidity (NTU) remains rather constant. Therefore, the jar-test protocol selected for the optimization of coagulation performance was rapidly mixed at 
$160 \mathrm{rpm}$ for $2 \mathrm{~min}$, slowly stirred at $40 \mathrm{rpm}$ for $10 \mathrm{~min}$, and finally, sedimentation was performed for $50 \mathrm{~min}$.

\subsubsection{Determination of the Optimum Dosage and Type of Material}

The coagulant dosage is considered to be among the most critical parameters that present a significant effect on the efficiency of the coagulation process. All prepared coagulants in this study were compared in terms of turbidity removal (Figure 5) (expressed as NTU units), in order to obtain the optimum type of coagulant and subsequently, to determine the optimal dosage of the examined materials by treating simulated surface water samples, noting that the respective initial values of this water were 17.2 NTU and pH $7.6 \pm 0.2$ (Table 2).
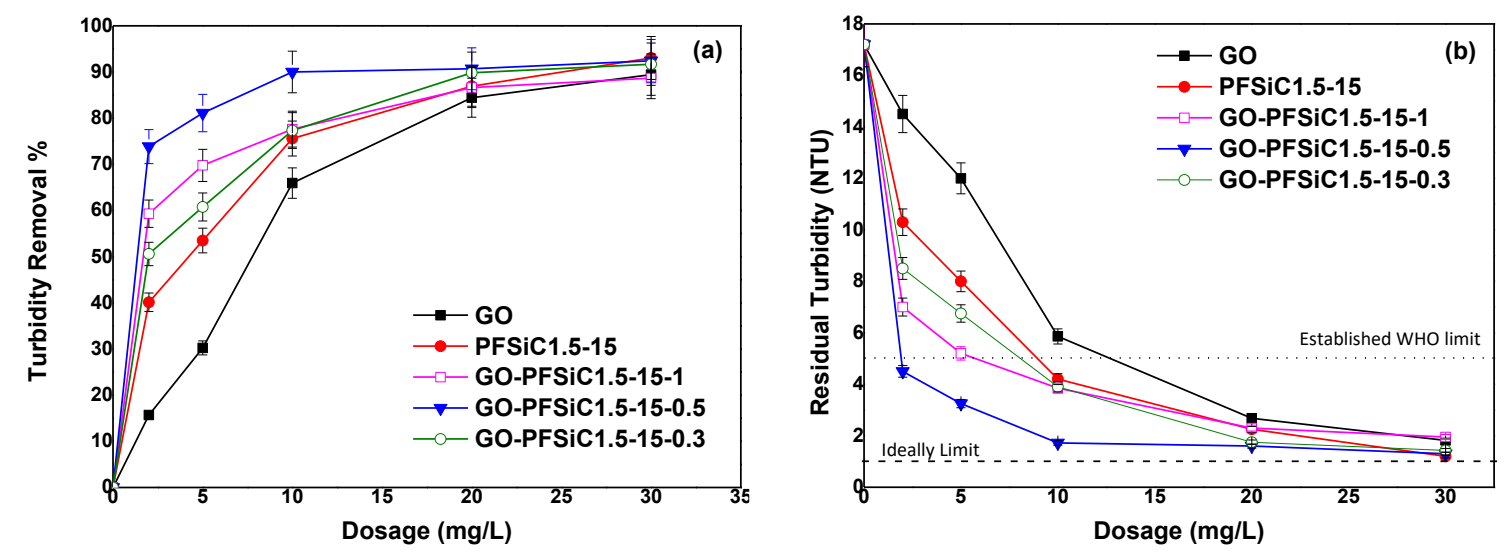

Figure 5. Determination of the optimum dosage and best material type, by comparing GO, PFSiC $1.5-15$, GO- PFSiC $1.5-15-1$, GO- PFSiC $1.5-15-0.5$, and GO- PFSiC $1.5-15-0.3$ materials, regarding the removal of turbidity, treating simulated surface water samples, expressed (a) as \% removal, and (b) as residual turbidity (NTU).

According to the obtained results, it can be observed that the application of composite/hybrid materials shows a better coagulation efficiency than the pure graphene oxide (GO) or the simple PFSiC $_{1.5-15}$ coagulant. Particularly, the composite GO-PFSiC $1.5-15-0.5$ with the ratio $[\mathrm{GO}] /[\mathrm{Fe}]=0.5$ was found to significantly reduce the turbidity for dosages above $3-5 \mathrm{mg} / \mathrm{L}$, i.e., much lower than the relevant data found in the respective literature, e.g., $>24 \mathrm{mg} / \mathrm{L}$ [23]. In addition, the turbidity removal was increased, as the dosage of GO-PFSiC $1.5-15-0.5$ was increased, reaching 93\% ( 1 NTU) for a dosage of $30 \mathrm{mg} / \mathrm{L}$. According to the recommendations from the World Health Organization [32], turbidity must be lower than 5 NTU before the water can be adequately sanitized for human consumption and should be ideally below than 1 NTU. It is worth noting that the optimum GO-PFSiC $1.5-15-0.5$ material, as illustrated in Figure 2d, presents the most uniform distribution of iron on the surface of graphene oxide.

\subsubsection{Determination of Optimum $\mathrm{pH}$}

The effect of $\mathrm{pH}$ on the coagulation ability of optimal GO-PFSiC $1.5-15-0.5$ material, as obtained from the previous experiments, was examined in the $\mathrm{pH}$ range 4-9, by using $10 \mathrm{mg} / \mathrm{L}$ of GO-PFSiC $1.5-15-0.5$. The removal of turbidity, expressed as percentage (Figure 6a) and as residual values (NTU) (Figure 6b), is presented in Figure 6. According to the results, it is found that the treated water by the composite material GO-PFSiC $1.5-15-0.5$ can follow the respective legislation (by WHO) limits with an increase of $\mathrm{pH}$ values over 8 . In particular, at more alkaline $\mathrm{pH}$ values $(>7.9)$, the removal of turbidity reaches $96 \%$, by applying only the $10 \mathrm{mg} / \mathrm{L}$ dosage, while in $\mathrm{pH} 6$, where very small flocks rather slowly formed and barely settled, the relative percentage decreases significantly $(68 \%)$. However, at $\mathrm{pH} 4-5$, the turbidity removal efficiency was highly improved (up to 75-85\%), in accordance with the relevant literature [23]. The original $\mathrm{pH}$ value of the examined simulated surface water (at $\mathrm{pH} 7.6 \pm 0.2$ ) was 
in the optimum $\mathrm{pH}$ range for the treatment of turbid water samples, in agreement with Figure 6. In strong alkaline media, the formation of flocks was very quick and began even from the first minute of high-speed agitation.
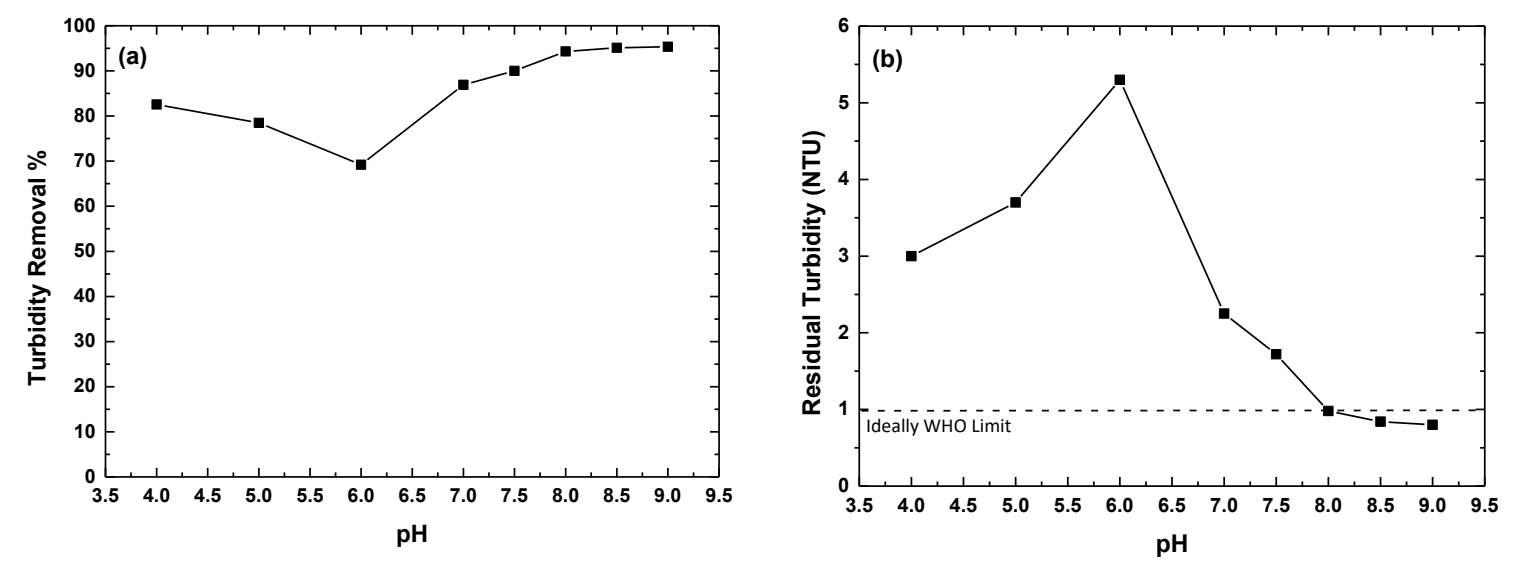

Figure 6. Effect of $\mathrm{pH}$ values on (a) \% turbidity removal, (b) residual turbidity, when treating simulated surface water samples, for an initial turbidity of $17.2 \mathrm{NTU}$ and coagulant dosage of $10 \mathrm{mg} / \mathrm{L}$, regarding the application of the optimal GO-PFSiC $1.5-15-0.5$ material.

\section{Conclusions}

This study presented the application of new composite materials obtained with the interaction between GO (graphene oxide) and PFSiC (polyferric silicate chloride), i.e., an Fe-based pre-polymerized coagulant agent, as a promising hybrid material to synergistically enhance water treatment. The hybrid GO-PFSiC derivatives are firstly reported in the literature.

The structure and morphology of composite GO-PFSiC coagulants were studied in detail by the application of FTIR, XRD, and SEM techniques. According to the presented results, the success of PFSiC loading on GO sheets was confirmed by the FTIR spectra at a wavenumber of $617.19 \mathrm{~cm}^{-1}$, corresponding to the Fe-O bond in the GO-PFSiC material. The XRD analysis confirmed the characteristic peaks of PFSIC $_{1.5-15}$ in the composites with GO, indicating that the PFSiC particles were distributed uniformly on the surface of graphene, especially in the composite GO-PFSiC $1.5-15-0.5$, which was also confirmed by the SEM images.

Furthermore, the proposed coagulants were applied for the treatment of simulated surface water contaminated with clay. The effects of the dosage, $\mathrm{pH}$, and experimental/operating conditions on the coagulation efficiency, regarding the removal of turbidity, were examined, aiming to determine the optimal turbidity removal conditions. The jar-test protocol selected for the best coagulation performance was rapid mixing at $160 \mathrm{rpm}$ for $2 \mathrm{~min}$, slow stirring at $40 \mathrm{rpm}$ for $10 \mathrm{~min}$, and finally, sedimentation for $50 \mathrm{~min}$. According to the obtained results, the composite material GO-PFSiC $1.5-15-0.5$ with the ratio $[\mathrm{GO}] /[\mathrm{Fe}]=0.5$ can significantly reduce the turbidity for dosages above $3-5 \mathrm{mg} / \mathrm{L}$, i.e., much lower than the respective presented values in the relevant literature. The effect of $\mathrm{pH}$ on the coagulation ability of $\mathrm{GO}-\mathrm{PFSiC}_{1.5-15-0.5}$ was tested in the $\mathrm{pH}$ range 4-9 by using a $10 \mathrm{mg} / \mathrm{L}$ dosage. It was found that the $\mathrm{GO}_{-\mathrm{PFSiC}}$ 1.5-15-0.5-treated water can follow the stringent legislation (by WHO) limits with an increase of the application $\mathrm{pH}$ values. In particular, at more alkaline $\mathrm{pH}$ values (>7.9), the removal of turbidity can reach $96 \%$, by applying only a $10 \mathrm{mg} / \mathrm{L}$ as dosage.

Consequently, the results of this study render these materials as potential coagulants for further research and potential applications regarding the co-removal of other water components.

Author Contributions: Data curation, A.K.T.; Investigation, A.K.T.; Methodology, A.K.T.; Writing-Original draft, A.K.T.; Validation, A.I.Z.; Visualization, A.K.T. and A.I.Z.; Writing-Review and editing, A.K.T. and A.I.Z.; Supervision, A.I.Z. All authors have read and agreed to the published version of the manuscript. 
Funding: This research was funded by the European Union and the Greek State Program EPAN-II (OPC-II)/ESPA (NSRF): SYNERGASIA II, Project (FOUL-MEM), grant number 11SYN-8-1084, entitled “New processes for fouling control in membrane bioreactors".

Acknowledgments: The Onassis Foundation for receiving A. Tolkou a scholarship to participate in a summer school at the Foundation of Research and Technology (FORTH), Crete, Greece, for Nanoscience and Nanotechnology, emphasizing on Graphene and other 2D materials, in which the winner of the Nobel Prize in Chemistry for the discovery of graphene, Konstantin Novoselov, taught.

Conflicts of Interest: The authors declare that they have no conflict of interest.

\section{References}

1. Simate, G.S.; Iyuke, S.E.; Ndlovu, S.; Heydenrych, M. The heterogeneous coagulation and flocculation of brewery wastewater using carbon nanotubes. Water Res. 2012, 46, 1185-1197. [CrossRef] [PubMed]

2. Zhao, G.; Jiang, L.; He, Y.; Li, J.; Dong, H.; Wang, X.; Hu, W. Sulfonated graphene for persistent aromatic pollutant management. Adv. Mater. 2011, 23, 3959-3963. [CrossRef] [PubMed]

3. Gallios, G.; Tolkou, A.; Katsoyiannis, I.; Stefusova, K.; Vaclavikova, M.; Deliyanni, E. Adsorption of arsenate by nano scaled activated carbon modified by iron and manganese oxides. Sustainability 2017, 9, 1684. [CrossRef]

4. Danô, M.; Viglašová, E.; Galamboŝ, M.; Rajec, P.; Novák, I. Sorption behaviour of pertechnetate on oxidized and reduced surface of activated carbon. J. Radioanal. Nucl. Chem. 2017, 314, 2219-2227. [CrossRef]

5. Deliyanni, E.A.; Kyzas, G.Z.; Triantafyllidis, K.S.; Matis, K.A. Activated carbons for the removal of heavy metal ions: A systematic review of recent literature focused on lead and arsenic ions. Open Chem. 2015, 13, 699-708. [CrossRef]

6. Giannakoudakis, D.A.; Kyzas, G.Z.; Avranas, A.; Lazaridis, N.K. Multi-parametric adsorption effects of the reactive dye removal with commercial activated carbons. J. Mol. Liq. 2016, 213, 381-389. [CrossRef]

7. Sweetman, M.J.; May, S.; Mebberson, N.; Pendleton, P.; Vasilev, K.; Plush, S.E.; Hayball, J.D. Activated carbon, carbon nanotubes and graphene: Materials and composites for advanced water purification. C J. Carbon Res. 2017, 3, 18. [CrossRef]

8. Novoselov, K.S.; Geim, A.K.; Morozov, S.V.; Jiang, D.; Zhang, Y.; Dubonos, S.V.; Grigorieva, I.V.; Firsov, A.A. Electric field effect in atomically thin carbon films. Science 2004, 306, 666-669. [CrossRef]

9. Geim, A.K.; Novoselov, K.S. The rise of graphene. Nat. Mater. 2007, 6, 183-191. [CrossRef]

10. Ghosh, S.; Calizo, I.; Teweldebrhan, D.; Pokatilov, E.P.; Nika, D.L.; Balandin, A.A.; Bao, W.; Miao, F.; Lau, C.N. Extremely high thermal conductivity of graphene: Prospects for thermal management applications in nanoelectronic circuits. Appl. Phys. Lett. 2008, 92, 151911-151913. [CrossRef]

11. Lu, Y.H.; Chen, W.; Feng, Y.P.; He, P.M. Tuning the electronic structure of graphene by an organic molecule. J. Phys. Chem. B 2009, 113, 2-5. [CrossRef] [PubMed]

12. Lee, C.G.; Wei, X.D.; Kysar, J.W.; Hone, J. Measurement of the elastic properties and intrinsic strength of monolayer graphene. Science 2008, 321, 385-388. [CrossRef] [PubMed]

13. Zhang, K.; Dwivedi, V.; Chi, C.; Wu, J. Graphene oxide/ferric hydroxide composites for efficient arsenate removal from drinking water. J. Hazard. Mater. 2010, 182, 162-168. [CrossRef] [PubMed]

14. Setshedi, K.Z.; Bhaumik, M.; Onyango, M.S.; Maity, A. High-performance towards Cr (VI) removal using multi-active sites of polypyrrole-graphene oxide nanocomposites: Batch and column studies. Chem. Eng. J. 2015, 262, 921-931. [CrossRef]

15. Mohamud, H.; Ivanov, P.; Russell, B.C.; Regan, P.H.; Ward, N.I. Selective sorption of uranium from aqueous solution by graphene oxide-modified materials. J. Radioanal. Nucl. Chem. 2018, 316, 839-848. [CrossRef]

16. Yang, A.; Zhu, Y.; Li, P.; Huang, C.P. Preparation of a magnetic reduced-graphene oxide/tea waste composite for high-efficiency sorption of uranium. Sci. Rep. 2019, 9, 6471. [CrossRef]

17. Tolkou, A.K.; Katsoyiannis, I.A.; Zouboulis, A.I. Removal of arsenic, chromium and uranium from water sources by novel nanostructured materials including graphene-based modified adsorbents: A mini review of recent developments. Appl. Sci. 2020, 10, 3241. [CrossRef]

18. Jastrzebska, A.M.; Kurtycz, P.; Olszyna, A.R. Recent advances in graphene family materials toxicity investigations. J. Nanopart. Res. 2012, 14, 1320-1340. [CrossRef]

19. Sanchez, V.C.; Jachak, A.; Hurt, R.H.; Kane, A.B. Biological interactions of graphene-family nanomaterials: An interdisciplinary review. Chem. Res. Toxicol. 2012, 25, 15-34. [CrossRef] 
20. Muscatello, J.; Jaeger, F.; Matar, O.K.; Müller, E.A. optimizing water transport through graphene-based membranes: Insights from nonequilibrium molecular dynamics. ACS Appl. Mater. Interfaces 2016, 8, 12330-12336. [CrossRef]

21. Alammar, A.; Park, S.-H.; Williams, C.J.; Derby, B.; Szekely, G. Oil-in-water separation with graphene-based nanocomposite membranes for produced water treatment. J. Membr. Sci. 2020, 603, 118007. [CrossRef]

22. Yang, Z.; Yan, H.; Yang, H.; Li, H.; Li, A.; Cheng, R. Flocculation performance and mechanism of graphene oxide for removal of various contaminants from water. Water Res. 2013, 47, 3037-3046. [CrossRef]

23. Abdelmeguid, E.; Aboubaraka, A.E.; Aboelfetoh, E.F.; Ebeid, E.-Z.M. Coagulation effectiveness of graphene oxide for the removal of turbidity from raw surface water. Chemosphere 2017, 181, 738-746.

24. Wen, X.; Jin, X.; Wang, F.; You, Y.; Chu, D.; Zetterlund, P.B.; Joshi, R.K. Cation-induced coagulation in graphene oxide suspensions. Mater. Today Chem. 2019, 13, 139-146. [CrossRef]

25. Zouboulis, A.I.; Moussas, P.A. Polyferric silicate sulphate (PFSiS): Preparation, characterization and coagulation behavior. Desalination 2008, 224, 307-316. [CrossRef]

26. Tzoupanos, N.D.; Zouboulis, A.I.; Tsoleridis, C.A. A systematic study for the characterization of a novel coagulant (polyaluminium silicate chloride). Colloids Surf. A Physicochem. Eng. Asp. 2009, 342, 30-39. [CrossRef]

27. Tolkou, A.K.; Zouboulis, A.I. Synthesis and coagulation performance of composite poly-aluminum-ferric-silicate-chloride coagulants in water and wastewater. Desalin. Water Treat. 2015, 53, 3309-3318. [CrossRef]

28. Tolkou, A.; Mitrakas, M.; Katsoyiannis, I.; Ernst, E.; Zouboulis, A. Fluoride removal from water by composite $\mathrm{Al} / \mathrm{Fe} / \mathrm{Si} / \mathrm{Mg}$ pre-polymerized coagulants: Characterization and application. Chemosphere 2019, 231, 528-537. [CrossRef]

29. Katsoyiannis, I.; Tzollas, N.; Tolkou, A.; Mitrakas, M.; Ernst, M.; Zouboulis, A. Use of novel composite coagulants for arsenic removal from waters-Experimental insight for the application of polyferric sulfate (PFS). Sustainability 2017, 9, 590. [CrossRef]

30. Tolkou, A.; Zouboulis, A. Application of composite pre-polymerized coagulants for the treatment of high-strength industrial wastewaters. Water 2020, 12, 1258. [CrossRef]

31. Gkotsis, P.K.; Mitrakas, M.; Tolkou, A.K.; Zouboulis, A.I. Batch and continuous dosing of conventional and composite coagulation agents for fouling control in a pilot-scale MBR. Chem. Eng. J. 2017, 311, 255-264. [CrossRef]

32. World Health Organization. Water Quality and Health-Review of Turbidity: Information for Regulators and Water Suppliers; WHO: Geneva, Switzerland, 2017.

33. Hummers, W.S.; Offeman, R.E., Jr. Preparation of graphitic oxide. J. Am. Chem. Soc. 1958, 80, 1339. [CrossRef]

34. Debnath, S.; Maity, A.; Pillay, K. Impact of process parameters on removal of Congo red by graphene oxide from aqueous solution. J. Env. Chem. Eng. 2014, 2, 260-272. [CrossRef]

35. Katsoyiannis, I.A.; Gkotsis, P.K.; Castellana, M.; Cartechini, F.; Zouboulis, A.I. Production of demineralized water for use in thermal power stations by advanced treatment of secondary wastewater effluent. J. Environ. Manag. 2017, 190, 132-139. [CrossRef]

36. Ramesha, G.K.; Kumara, A.V.; Muralidhara, H.B.; Sampath, S. Graphene and graphene oxide as effective adsorbents toward anionic and cationic dyes. J. Colloid Interface Sci. 2011, 361, 270-277. [CrossRef]

37. El-shafai, N.M.; El-khouly, M.E.; El-kemary, M. Fabrication andcharacterization of graphene oxide-titanium dioxidenanocomposite for degradation of some toxic insecticides. J. Ind. Eng. Chem. 2019, 69, 315-323. [CrossRef]

38. Neolaka, Y.A.B.; Lawa, Y.; Naat, J.N.; Riwu, A.A.P.; Iqbal, M.; Darmokoesoemo, H.; Kusuma, H.S. The adsorption of $\mathrm{Cr}(\mathrm{VI})$ from water samples using graphene oxide-magnetic $\left(\mathrm{GO}-\mathrm{Fe}_{3} \mathrm{O}_{4}\right)$ synthesized from natural cellulose-based graphite (kusambi wood or Schleichera oleosa): Study of kinetics, isotherms and thermodynamics. J. Mater. Res. Technol. 2020, 9, 6544-6556. [CrossRef]

39. Moussas, P.A.; Zouboulis, A.I. Synthesis, Characterization and coagulation behavior of a composite coagulation reagent by the combination of Polyferric Sulphate (PFS) and cationic polyelectrolyte. Sep. Purif. Technol. 2012, 96, 263-273. [CrossRef]

40. Sammaiah, A.; Huang, W.; Wang, X. Synthesis of magnetic $\mathrm{Fe}_{3} \mathrm{O}_{4}$ /graphene oxide nanocomposites and their tribological properties under magnetic field. Mater. Res. Express 2018, 5, 105006. [CrossRef] 
41. Danesh, N.; Hosseini, M. Magnetite graphene oxide/Lauric acid nanoparticles modified by ethylenediaminetetra acetic acid and its applications as an adsorbent for the removal of $\mathrm{Pb}$ (II) ions. Synth. Met. 2016, 220, 508-523. [CrossRef]

42. Guo, J.; Wang, R.; Tjiu, W.W.; Pan, J.; Liu, T. Synthesis of Fe nanoparticles@graphene composites for environmental applications. J. Hazard. Mater. 2012, 225, 63-73. [CrossRef] [PubMed]

43. Liu, P.; Zhong, W.; Wu, X.; Qiu, J. Facile synergetic dispersion approach for magnetic $\mathrm{Fe}_{3} \mathrm{O}_{4} @$ graphene oxide/polystyrene tri-component nanocomposite via radical bulk polymerization. Chem. Eng. J. 2013, 219, 10-18. [CrossRef]

44. Raghu, M.S.; Kumar, K.Y.; Prashanth, M.K.; Prasanna, B.P.; Vinuth, R. Adsorption and antimicrobial studies of chemically bonded magnetic graphene oxide-Fe3O4 nanocomposite for water purification. J. Water Process. Eng. 2017, 17, 22-31. [CrossRef]

(C) 2020 by the authors. Licensee MDPI, Basel, Switzerland. This article is an open access article distributed under the terms and conditions of the Creative Commons Attribution (CC BY) license (http://creativecommons.org/licenses/by/4.0/). 